\title{
LA PROFESIÓN DOCENTE Y LAS TEORÍAS IMPLÍCITAS SOBRE LA ENSEÑANZA. UNA REFLEXIÓN CRÍTICA
}

\author{
Dina Beltrán López* \\ Universidad Autónoma de Sinaloa
}

\section{RESUMEN}

A partir de un ejercicio de reflexión sobre la relación entre profesión docente y las teorías implícitas sobre la enseńanza, en este artículo se analiza la necesidad de estudiar el pensamiento de los profesores como un camino para coadyuvar a la mejora de la educación. Se examinan algunos rasgos de la profesión docente que se requieren en estos tiempos de complejidad e incertidumbre y se plantea la necesidad de crear condiciones para que los docentes abandonen el estatus de técnicos y se transformen en profesionales de la enseñanza con un adecuado dominio de los conocimientos inherentes a su campo y un espíritu crítico tanto de su práctica docente como del entorno en que se desenvuelve.

PALABRAS ClAVE: profesión docente, teorías implícitas, teorías implícitas sobre la enseñanza.

\section{THE TEACHING PROFESSION AND THE IMPLICIT THEORIES \\ ABOUT TEACHING. A CRITICAL REFLECTION}

\section{Abstract}

From an exercise of reflection on the relationship between the teaching profession and the implicit theories about teaching, this article analyzes the need to study teachers' thinking as a way to contribute to the improvement of education. It has been pondered on some of the features of the teaching profession that are required in these times of complexity and uncertainty and, based on this arises the need to create conditions for teachers to abandon the technicians status so they transform into teaching professionals who have an adequate knowledge mastery inherent to their field and a critical spirit in their teaching practice as well as in the atmosphere in which they operate.

KEYwOrds: teaching, implicit theories, implicit theories about teaching. 


\section{INTRODUCCIÓN}

Bajo la consideración de que las comunidades académicas del ámbito educativo caminan desde hace algunos años hacia el consenso respecto a la necesidad de volver la mirada hacia los maestros en tanto agentes fundamentales que deben y deberán tener un papel de primer orden para enfrentar la actual crisis educativa mundial, en este artículo se desarrolla un ejercicio de reflexión sobre la relación entre la profesión docente y las teorías implícitas sobre la enseñanza.

El planteamiento se basa en el supuesto de que cualquier intento de reforma educativa debe partir de efectuar una seria y profunda revisión de la profesión docente, la cual tiene que pasar, de manera obligada, por esfuerzos para conocer el pensamiento de los profesores. Diversos resultados de la investigación educativa indican que las teorías implícitas (Arévalo, 2010; 2013; Gómez \& Guerra, 2012; Lazcano, Santa Cruz \& Conget, entre otros) ofrecen un potencial explicativo-comprensivo que nos puede acercar a este conocimiento para, a partir de él, pensar, diseñar e implementar planes, programas y estrategias que incidan en su transformación. Así, pues, cobra relevancia conocer qué piensan los profesores respecto a lo que ocurre en las aulas, cuáles son las concepciones, creencias y teorías (la mayoría de las veces no declaradas) que guían su práctica y cuál consideran que es su papel en estos tiempos de cambios dinámicos en una sociedad compleja y profundamente desigual.

El texto se organiza en tres apartados: el primero trata de manera muy general y breve la crisis educativa que se vive en México y en el mundo; en el segundo, se realiza un acercamiento conceptual a las categorías profesión docente y teorías implícitas en la enseñanza; y en el tercero, se hacen algunas reflexiones sobre los desafíos que enfrenta la profesión docente en los tiempos actuales, a la luz de las teorías implícitas sobre la enseñanza como marco teórico-conceptual.

\section{LA CRISIS EDUCATIVA}

Hoy en día se reconoce que la escuela está en crisis y que incumple su misión de formar de manera adecuada a las nuevas generaciones. La discusión de estos asuntos tiene carácter central en los diversos eventos donde se aborda lo educativo, constituye un tema transversal de los programas curriculares relacionados con el área, es parte de los discursos de políticos y funcionarios, es preocupación cotidiana de educadores, constituye punto de partida de multitud de trabajos de investigación, lo perciben los educandos de los distintos niveles y es inquietud de

*E-mail: dinabelt@uas.edu.mx. Es licenciada en Ciencias de la Educación y doctora en Educación por el Centro Mar de Cortés, Sinaloa. Es integrante del Sistema Nacional de Investigadores Nivel Candidata del CONACyT. Sus intereses de investigación se enfocan en el estudio de la historia de la educación. Responsable del Archivo Histórico de la Biblioteca Central de la Universidad Autónoma de Sinaloa. 
padres de familia; en fin, por ser algo que a todos importa e inquieta, está colocado como uno de los temas principales de la agenda de los gobiernos de los diversos países, pues se reconoce la educación como un rubro en el que nunca se alcanza el nivel óptimo.

De manera cruda, Palacios (1997, p. 11) dibuja la realidad presente en las escuelas, afirmando que «no sería muy exagerado decir que la escuela está, cada vez más y a todos los niveles, generando una dolorosa frustración que abarca a todos sus estamentos». Al respecto, Pérez Gómez (2010) comenta que

... se ha convertido en lugar común la percepción generalizada de insatisfacción respecto a la calidad de los procesos de enseñanza-aprendizaje que tienen lugar en la escuela contemporánea. El abultado índice de abandono temprano de los estudiantes más necesitados, sin ni siquiera concluir la etapa obligatoria, y la irrelevancia de los contenidos que se aprenden para pasar exámenes, pero que no incrementan el conocimiento útil que aplica cada ciudadano a la mejor comprensión de la compleja vida cotidiana, personal, social y profesional, vuelven la mirada de la sociedad hacia la reforma drástica de un dispositivo escolar mejor adaptado a los requerimientos del siglo xix que a los desafíos del xxi (p. 38).

A pesar de que se reconoce la situación problemática que impera en las instituciones escolares del mundo, y de que ha habido interés por buscar y plantear soluciones que le pongan remedio, lo cierto es que hasta el momento no se han encontrado salidas a lo que, a todas luces, pareciera ser un callejón sin salida. Dado que se acepta que el asunto no es fácil y parece estar estancado, la búsqueda e implementación de soluciones está abierta.

Investigaciones educativas diversas (Delval, 199; Nóvoa, 2009; Rivero \& Porlán, 1998) concluyen que parte importante de la solución a la problemática de la educación debe partir de reconocer la necesidad de volver nuestra mirada hacia los docentes por ser los elementos clave para llevar a cabo una verdadera reforma. Bajo el influjo de los aires globalizadores neoliberales que soplan sobre el mundo de nuestros días, el campo de la formación del magisterio se ha visto seriamente afectado, observándose en las últimas décadas que la profesión docente ha venido sufriendo un proceso de devaluación en la que se ha impuesto una «orientación de la formación técnica para el ejercicio de la profesión, frente a la opción de formación multidisciplinaria propia de las carreras profesionales del campo de las ciencias sociales y las humanidades» (Rosales, 2004, p. 233).

Este tipo de formación que se impulsa desde la propuesta curricular de las instituciones formadoras de docentes tiene profundas repercusiones, pues año con año egresan de ellas técnicos de la enseñanza, más que profesionales, cuyo perfil en cuanto a formación, información y actitudes frecuentemente se asocia a egresados con bajos niveles de conciencia y de "capacidad comprensivo-explicativa de la realidad sociopolítica, económica y cultural» en que se desenvuelven (Rosales, 2004, p. 200).

Desde luego que reformar el sistema educativo de un país significa revisarlo todo, pero la parte que sigue de este trabajo se centra en analizar de qué manera puede coadyuvar a la mejora de la educación el estudio del pensamiento de los profesores desde el marco conceptual de las teorías implícitas sobre la enseñanza (Marrero, 
1993) para, a partir de ahí, reflexionar sobre el perfil de la profesión docente que se requiere en estos tiempos de complejidad e incertidumbre.

\section{PROFESIÓN DOCENTE Y TEORÍAS IMPLÍCITAS DE LA ENSEÑANZA}

Con el propósito de tener las lentes apropiadas para el análisis del tema que nos ocupa, en este apartado se recogen distintas conceptualizaciones sobre la profesión docente y las teorías implícitas. Estas últimas se abordan primero en general y después las que se relacionan con la enseńanza de manera particular.

\section{LA PROFESIÓN DOCENTE: UN ACERCAMIENTO CONCEPTUAL}

De acuerdo con Rodríguez y Guillén (1992, p. 9), una de las características fundamentales del siglo xx es el desarrollo de las profesiones, lo cual es -en su opinión- resultado de los avances del conocimiento y la creciente complejidad de las sociedades. Afirman estos autores que «un número cada vez mayor de parcelas de la vida social e individual se están convirtiendo en campos del conocimiento y de ejercicio de un creciente número de expertos profesionales»; y es a partir de ello que se ha suscitado el interés de la sociología por abonar a la construcción teórica en este campo.

El concepto de profesión tiene por lo menos tres cualidades: es histórico, concreto y tiene un carácter dinámico; y a ello se debe que más que definiciones únicas lo que se tiene es un constructo en el que abunda la polisemia (Freidson, 2001). No obstante, cabe precisar que el mayor desarrollo conceptual del término tiene localización geográfica muy precisa, pues han sido las escuelas anglosajona y francesa las que más se han preocupado por el tema.

Si bien la emergencia del estudio de las profesiones suele ubicarse en el mundo anglosajón en la década de 1930, corresponde a Herbert Spencer (18201903) la primera conceptualización del término. Desde el marco de la sociología evolucionista, al finalizar el siglo xx, este autor consideró que las profesiones se circunscribían a la complejidad social y su función era proporcionar bienestar y mejorar la calidad de vida de las personas («aumentar la vida»). Éstas tienen su punto de partida en la organización político-eclesiástica primitiva, la que, al dividirse en política y eclesiástica, da como resultado que las profesiones se desenvuelvan a partir de su elemento político (Spencer, 1992, pp. 316-317).

Corresponde a Andrew Abbott (1988, citado en Canaleta-Safon, 2013, p. 9) la aportación de una clasificación de las diferentes escuelas que han contribuido al desarrollo teórico conceptual de la sociología de las profesiones: la definidora, la evolucionista y la revisionista. La primera, que se sitúa entre los años 30 y 50 del siglo xx, se enmarca en la corriente funcionalista y plantea que las profesiones son un medio de control de las relaciones asimétricas entre profesio- 
nal y cliente. Su principal representante, Emilio Durkheim (1858-1917), plantea entre otras cosas que:

- La moral profesional ocupa un lugar intermedio entre la moral familiar y la cívica.

- Todas las profesiones tienen su moral, menos las económicas (anarquía o vacío moral).

- Es importante que la vida moral (la de los empresarios y trabajadores de la industria y del comercio) esté sometida a reglas morales.

- La moral no se improvisa, es obra de un grupo. Para moralizar la vida económica tienen que constituirse o reconstituirse los gremios profesionales.

- Un consejo de administración, elegido, debe regular a nivel nacional lo que concierne a cada profesión (citado en Hortal, 2002).

Por su parte, la escuela evolutiva tiene como marco el estructuralismo y comprende de los ańos 50 a mediados de los 60 del siglo xx. Plantea que la profesión es una forma de control ocupacional, en la que el contenido del trabajo y las relaciones profesional-cliente no revisten mucha importancia Los teóricos agrupados en esta escuela pusieron atención en las características especiales del conocimiento, la pericia de los profesionales y el carácter altruista de sus actividades. También continuaron con su intento por clarificar la definición de profesión y en este periodo aparece el término profesionalización. Sus principales exponentes son Talcott Parsons, de la corriente estructuralista, y Hughes, de la Escuela de Chicago (Canaleta-Safon, 2013, pp. 12-13). Al introducir el término «ideología de servicio», Parsons (1951) consideró que en el desempeño de las funciones de los profesionales -en especial de los médicos- no debía primar el ánimo de lucro, sino más bien cierto altruismo, una orientación básica para favorecer a la colectividad (Parsons, 1951).

Y, por último, la escuela revisionista -que abarca de 1970 hasta la actualidad- tiene como marco el neoweberismo, el neomarxismo y la etnometodología, que utilizan los conceptos de autonomía, poder y monopolio. Esta escuela acepta la base estructural pero no se contempla como un desarrollo "natural» sino como un deseo de dominio y/o autoridad. Las características generales son, entre otras:

- Se ataca a los profesionales y se abandona el estudio de las normas profesionales y la relación con los clientes.

- Los atributos profesionales ya no se contemplan como atributos ideales, sino como instrumentos para aumentar su poder con respecto a otros grupos sociales.

- Las actividades profesionales se empiezan a analizar en términos políticos y la autonomía como atributo clave del profesionalismo.

- La vocación de servicio se sustituye por una visión en la cual los profesionales son los creadores de las necesidades y de las formas de servirlas a los consumidores o clientes.

- El mercado es fuerza en el proceso de profesionalización (Canaleta-Safon, 2013, pp. 16-17). 
Con base en el análisis de Flexner en 1915, en su trabajo titulado Is Social Work a Profession? Dubar y Tripier (1998, citados en Panaia, 2008) retoman el debate sobre las características comunes a todas las profesiones, y las resumen en los siguientes cinco puntos:

1. Las profesiones tratan de operaciones intelectuales asociadas a las grandes responsabilidades individuales.

2. El material de base de su actividad es extraído de la ciencia y de su saber teórico; sus saberes teóricos comportan aplicaciones prácticas y útiles.

3. Sus saberes son transmisibles por la enseñanza formalizada.

4. Las profesiones tienden a la autoorganización en asociaciones.

5. Sus miembros tienen una motivación altruista.

De acuerdo con Panaia (2008), al relacionarse el término profesión con la calificación y las competencias, se reconocen cuatro sentidos diferentes en su utilización: la profesión como declaración de principios, como empleo, como oficio y como función; correspondiendo la primera a la identidad profesional, la segunda a la calificación profesional, la tercera a la especialización y la última a la posición profesional.

Dentro del mundo de las profesiones, la de la docencia es una de las más estudiadas. Así, desde el siglo XviI Juan A. Comenio propuso en su Didáctica Magna que el profesor debía «enseñar todo a todos» (Comenio, 1982, p. 33) y, a partir de él, han sido innumerables los educadores y pedagogos que han planteado visiones particulares de la docencia. En las diversas concepciones, el docente ha sido caracterizado de distintas maneras y desde diversos miradores, que pueden resumirse en que se le considera un líder social responsable de la formación y continuidad sociocultural de las generaciones venideras (Dorfsman, 2012).

En el sentido moderno y de manera general, el término "profesión» se refiere a un tipo de trabajo al que una persona se dedica de manera habitual. No obstante, éste ha sido desarrollado de distintas maneras y una de ellas, importante de retomar, es el de la Organización Internacional del Trabajo (OIT), que plantea que es una ocupación intelectual, cuyo ejercicio requiere profundos conocimientos y calificaciones que comúnmente se adquieren en ciclos superiores en los diversos campos del conocimiento (1995, pp. 54 y 59).

De acuerdo con los diversos enfoques y conceptualizaciones con que se ha estudiado la profesión docente, Dorfsman (2012) plantea una caracterización que toma en cuenta por lo menos cuatro dimensiones. En primer lugar, la que considera que la profesión docente incluye la apropiación de un saber académico-disciplinar el cual puede ocupar un lugar central, preeminente o simplemente accesorio. La segunda dimensión es la del saber pedagógico, que es el componente central de la profesión docente. En la tercera dimensión se plantean como rasgos centrales de la profesión el saber técnico-pedagógico, el saber disciplinar y el compromiso moral con la comunidad. Y, por último, la cuarta dimensión es la personal-reflexiva, que coloca al alumno en el centro de la preocupación de la tarea educativa. En esta última dimensión se ubican tanto la pedagogía de la liberación de Paulo Freire (1981) como la práctica reflexiva propuesta por Schön (1998). 
Otra forma de abordar la conceptualización de la profesión docente es considerando los diferentes tipos de conocimientos que deben asociarse a ella. Desde la perspectiva de Grossman (1990, citado en Marrero, 2010, pp. 234-235) existen los siguientes cinco tipos de conocimientos docentes:

- Conocimiento pedagógico general. Se relaciona con los principios de la enseñanza, con el aprendizaje de los alumnos, la enseñanza en pequeños grupos, la gestión de clase, las técnicas didácticas, la estructura de la clase, la planificación de la enseñanza, las teorías del desarrollo humano, la planificación curricular, la evaluación, la cultura social y la influencia del contexto en la enseñanza, la historia y filosofía de la educación, los aspectos legales de la educación.

- Conocimiento de la materia. Es el saber sobre la asignatura que se enseńa que debe traducirse en el buen manejo de la disciplina a impartir. Este conocimiento influye tanto en los contenidos (el qué enseñar) como en los métodos y técnicas de enseñanza (el cómo enseñar).

- Conocimiento del contenido. Incluye los componentes relacionados con el conocimiento sintáctico (el cuerpo de conocimientos generales de una materia, los conceptos específicos, las convenciones y los procedimientos); y los referentes al conocimiento sustantivo (los paradigmas de investigación en cada disciplina, el conocimiento relativo a cuestiones como la validez, tendencias y perspectivas en el campo de su especialidad).

- Conocimiento didáctico del contenido. Representa la combinación adecuada del conocimiento de la materia a enseñar con el conocimiento pedagógico y didáctico referido a la manera de enseńarla.

- Conocimiento contextual. Permite adaptar el conocimiento general de la materia a los alumnos, a las condiciones particulares de la escuela y a las situaciones específicas.

En su trabajo sobre la profesión docente, Goodson y Hargreaves (1996, pp. 4-19) agrupan las diferentes acepciones en torno a cinco formas de entender la profesión docente:

- Profesionalismo clásico. Se fundamenta en la comparación de la enseñanza con las profesiones con alto estatus social como la medicina y el derecho, que se caracterizan por tener un conocimiento profesional común o cultura técnica compartida (conocimiento científico), una ética hacia el servicio a los clientes y la autorregulación por sus propias organizaciones.

- Profesionalismo flexible. La clave está en la cultura de colaboración que surge en las comunidades de prácticos. Dado que el conocimiento científico base sobre la educación - generado a través de una investigación de corte empirista- presenta problemas epistemológicos, se promocionan comunidades de profesionales que trabajan colaborativamente, las cuales se desempeñan en sus contextos particulares y sobre sus áreas específicas, compartiendo sus problemas e inquietudes con vistas a la mejora de su labor docente, que 
se produce mediante la construcción compartida de los significados de su práctica profesional.

- Profesionalismo práctico. Procura dar dignidad y estatus al conocimiento práctico que las personas tienen respecto a la tarea que realizan. La validez y pertinencia de la experiencia docente, que se consideró en otros momentos como una debilidad de la profesión, en esta acepción se valora como fundamental y por tanto una fuente válida de conocimiento, más allá de la oposición teoría-práctica. Entre sus sustentos están los planteamientos de Elbaz, Connelly y Clandinin, quienes afirman que las rutinas y el conocimiento que tienen los profesores sobre cómo hacer su trabajo constituyen el conocimiento práctico personal o conocimiento del oficio; así como el concepto de enseñanza como práctica reflexiva de Donald Schön.

- Profesionalismo expandido. Frente a un profesionalismo en regresión en el que la enseñanza es vista como una tarea de naturaleza intuitiva (las habilidades derivan de la experiencia, los acontecimientos de clase se perciben aisladamente, la metodología se concibe como introspección, se valora la autonomía individual, hay escasa participación en actividades distintas a las profesionales, las actividades se limitan a las de carácter práctico), el profesionalismo expandido deriva sus conocimientos de la relación entre teoría y práctica, la perspectiva del profesor va más allá de la clase, para abrazar el contexto social más amplio de la educación; los sucesos de clase se perciben en relación con otros aspectos de la escuela, compara su metodología con la de otros, valora las actividades profesionales, lee literatura profesional, asiste a actividades de formación teórico-prácticas; en suma, la enseñanza es vista como una actividad racional, no intuitiva. Goodson y Hargreaves (1996, pp. 16-17) se inclinan más por el término profesionalismo dilatado, producto de la participación con cierto grado de obligatoriedad con mayor número de actividades y reuniones de planificación colectiva, que del auténtico compromiso que implica el profesionalismo expandido.

- Profesionalismo complejo. Se fundamenta en que las profesiones deben juzgarse por la complejidad del trabajo que realizan y, por ende, esta categoría debe estar presente en la enseńanza con todo lo que ello implica. Esta complejidad se apoya en que se necesitan habilidades de resolución de problemas, la implementación de estrategias de aprendizaje cooperativo y habilidades de pensamiento complejo para intervenir en contextos de incertidumbre. Considera que todos los profesores deben ser líderes de sus estudiantes y, como tales, conducir procesos de gran complejidad.

Como puede verse en las ideas expuestas, la profesión docente está sujeta a diversos miradores epistemológicos que deben tenerse presentes, ya que ellos son expresión del debate sobre el qué y para qué de esta profesión que ha ocupado un lugar central a lo largo de la historia y que también hoy está en el foco de la atención de los investigadores y de los propios docentes, en aras de problematizarla y formular propuestas para mejorarla y que ello se traduzca en la mejora de los procesos de enseñanza en nuestras escuelas. Esto es, porque del tipo de docente que se impulse 
será nuestra visión de la educación, la cual, al final de cuentas, se mueve entre la gran tensión de formar para reproducir o formar para transformar.

\section{TEORÍAS IMPLÍCITAS SOBRE LA ENSEÑANZA}

El desarrollo de las ciencias cognitivas ha traído consigo una nueva revolución de la ciencia, en la medida en que los sistemas cognitivos o representacionales que son su objeto de estudio difieren de los sistemas físicos o biológicos hasta ahora estudiados por la ciencia. Un sistema cognitivo es un dispositivo que construye representaciones del mundo que le permiten predecir y controlar los cambios físicos que tienen lugar en él. La mente humana es un dispositivo representacional muy complejo, capaz de generar diversos tipos de representación, pero que también está en la posibilidad de

... acceder a sus propias representaciones, de hacerse de algún modo consciente de ellas, y convertirlas en meta-representaciones o conocimiento propiamente dicho, que puede ser comunicado o explicitado a través de diferentes sistemas de representación (el lenguaje oral, la escritura, la notación matemática, gráficos y calendarios, etc.) (Pozo, 2002, p. 248).

El estudio de estas representaciones ha sido el objeto de la psicología cognitiva a través del procesamiento de la información como enfoque predominante, el cual se basó en sus inicios en la analogía funcional entre la mente y la computadora. Mientras que al principio los estudios de esta ciencia consideraron que la mente era proposicional, simbólica, semántica, declarativa abstracta, explícita e individual, años después las investigaciones obligaron a los psicólogos cognitivos a aceptar una mente con imágenes, episodios y acciones situadas, con representaciones distribuidas e implícitas, y caracterizada por ser interpersonal y socialmente distribuida. Este vuelco de las investigaciones ocurrió por la crisis de los modelos computacionales clásicos, lo que dio lugar al cambio de la metáfora de la memoria como símil de la biblioteca por el de la nebulosa (Pozo, 2002, p. 249).

De ahí que Donald (2001, citado en Pozo, 2002) hiciera el planteamiento de que la mente humana es híbrida, ya que está compuesta por dos sistemas muy diferentes, uno dedicado a representar el mundo concreto, cercano, mediante acciones y precepciones, cuyas metas son esencialmente pragmáticas, es decir, dirigidas a la predicción y el control rápido de sucesos concretos; y otro supuestamente más racional y abstracto que usa lenguajes formales y puede comunicarse a través de ellos, cuyas metas son más epistémicas, como son el conocimiento o explicación reflexiva de esos sucesos.

El estudio de las representaciones implícitas ha tenido un desarrollo inusitado a partir de la década de 1980. Su investigación reciente en dominios específicos se ha desarrollado, de acuerdo con Wellman y Gelman (1997, citados en Pozo, 2002, p. 257), desde tres perspectivas teóricas que asumen supuestos distintos sobre la naturaleza y organización de esas representaciones, que se corresponden con las 
tres concepciones que existen sobre el origen del conocimiento humano: el empirismo, el racionalismo y el constructivismo. Dichas perspectivas son:

Primera. Concibe el desarrollo de las representaciones como la adquisición de pericia en ciertos dominios y se apoya en la psicología de la instrucción y en los estudios que comparan a los expertos y los novatos. Este enfoque, de bases epistemológicas empiristas, implica aceptar que el conocimiento tiene su origen en la práctica de cualquier dominio nuevo o arbitrario en la que éste se acumule.

Segunda. Asume que las representaciones tienen su origen en ciertos módulos cognitivos innatos, es decir, en estructuras y principios de procesamiento genéticamente dados. Según este enfoque - de corte racionalista-, el conocimiento se basa en dispositivos especializados para el procesamiento de la información, los cuales se caracterizan por ser preformados. Se niega la existencia de mecanismos para hacer posible el cambio de representaciones y se ocupan de sistemas cognitivos nucleares que intentan identificar «universales cognitivos».

Tercera. Sostiene que nuestras representaciones implícitas constituyen teorías de dominio, es decir, sistemas de representación, organizados y consistentes, basados en principios que restringen el procesamiento de la información en ese dominio, pero que pueden ser revisados y explicitados como consecuencia del aprendizaje. Aunque al interior del enfoque hay variantes, todas coinciden en que aceptan que nuestras representaciones implícitas se organizan en forma de teorías implícitas. Estos planteamientos coinciden con los postulados del constructivismo como concepción epistemológica.

De acuerdo a Gopnik y Meltzoff (1997, citado en Pozo, 2002, pp. 258259), las teorías de dominio a que se hace referencia en la tercera perspectiva comparten cuatro rasgos: la abstracción (los constructos teóricos son leyes o principios de naturaleza abstracta); la coherencia (las representaciones surgidas de una teoría están "legalmente» relacionadas entre sí, de forma que son unidades de información conectadas); la causalidad (los principios teóricos y las representaciones que de ellos se derivan sirven para explicar o dar cuenta de las regularidades del mundo); y el compromiso ontológico (las teorías restringen las representaciones posibles, asumiendo la necesidad de un determinado orden ontológico, cuya violación exige una revisión de la teoría).

Pozo (2002, p. 261) sostiene que asumir que las representaciones de dominio constituyen teorías de naturaleza implícita requiere justificar dos cosas: primera, que poseen las propiedades enunciadas en el anterior párrafo con respecto a las teorías; y, segunda, que su naturaleza implícita significa que las personas que hacen un uso pragmático no pueden hacer un uso epistémico pleno de ellas, es decir, desconocen, en parte o en todo, que usan esas teorías para representarse el mundo. Sobre este punto particular, Marrero (2009, p. 231; 2010, p. 35) sostiene que son "teorías» porque componen un conjunto más o menos organizado de conocimiento sobre el mundo físico o social, aunque su grado de organización y coherencia interna dista 
mucho de parecerse a las teorías científicas; y que deben su carácter implícito a que no suelen ser accesibles a nuestra conciencia.

Con base en la investigación generada de este campo y sus estudios sobre el sentido común, Castorina, Barreiro y Toscano (2005) señalan los siguientes cuatro rasgos de las teorías implícitas:

a) Su carácter implícito. Significa que son inaccesibles a la conciencia individual y su formato representacional no puede ser explicitado de manera verbal por los individuos porque los argumentos que contienen son tácitos y sin especificar; simplemente se utilizan.

b) Son adaptativas. Se vinculan con un saber hacer, ya que se utilizan sin poder formularlas de manera explícita. Se trata de un conocimiento destinado a adecuarse a la exigencia de tomar decisiones para la acción (función pragmática), pero sin cuestionar la verdad o falsedad del mismo.

c) Son elaboraciones personales. Parten de experiencias individuales, lo que no implica la ausencia de alguna pauta sociocultural. Al contrario, los autores afirman que «las experiencias socioculturales se constituyen en la materia prima para la inducción personal de las TI [teorías implícitas], ya que la información de origen cultural es procesada cognitivamente» (Castorina et al., 2005, p. 205).

d) Responden a las demandas de los escenarios concretos en los que se producen. Explican y predicen situaciones vividas y tienen un estatus mental porque constituyen un registro de las mismas. De ahí que sólo se les puede interpretar como respuestas a demandas específicas que les plantea el entorno vital.

Las teorías implícitas pueden tener aplicación en diversos temas de investigación. Los estudios más relevantes desde esta perspectiva se han ocupado de las teorías de los profesores sobre la enseńanza, de los alumnos sobre el aprendizaje, de los adolescentes sobre el medio ambiente y de los niños sobre el dibujo (Castorina et al., 2005, p. 203). En el caso de México, destaca el estudio de Hernández (2008) sobre la lectura y el conocimiento metatextual en estudiantes de distintos niveles educativos (secundaria, bachillerato y educación superior).

Marrero (1993) hace una sistematización de las teorías implícitas sobre la enseñanza y las agrupa en cinco tipos que relaciona con distintos modelos pedagógicos. En la tabla 1 se recoge esta clasificación.

\begin{tabular}{|c|c|c|}
\hline Tipo de TEORÍA & Características & $\begin{array}{l}\text { Modelo PEDAGógico } \\
\text { AL QUE SE ASOCIA }\end{array}$ \\
\hline Dependiente & $\begin{array}{l}\text { Enseñanza guiada y dirigida por el profesor, de tal forma que se } \\
\text { mantiene un mismo ritmo de aprendizaje para todos los alum- } \\
\text { nos; se piensa que, si el profesor no enseña, los alumnos no son } \\
\text { capaces de aprender por sí solos; se postula una actitud distante } \\
\text { con los alumnos y una concepción de la escuela al margen de los } \\
\text { conflictos sociales y políticos. }\end{array}$ & Tradicional \\
\hline
\end{tabular}




\begin{tabular}{|c|c|c|}
\hline Productiva & $\begin{array}{l}\text { La enseńanza es la búsqueda de resultados y potenciación de la } \\
\text { eficacia en la enseńanza y el aprendizaje. Adquiere relevancia la } \\
\text { enseñanza por objetivos. }\end{array}$ & Técnico \\
\hline Expresiva & $\begin{array}{l}\text { Reconoce la actividad del estudiante como el núcleo funda- } \\
\text { mental del proceso de enseñanza aprendizaje. Los indicadores } \\
\text { permanentes son la experimentación, la educación para la vida, } \\
\text { la "cantidad» de actividades a realizar y la ocupación permanente } \\
\text { del alumno. }\end{array}$ & Activo \\
\hline Interpretativa & $\begin{array}{l}\text { Coinciden una pedagogía centrada en el alumno (sus necesida- } \\
\text { des, recursos y procesos de aprendizaje) y una actitud interpre- } \\
\text { tativa (búsqueda de explicaciones más o menos formalizada de } \\
\text { las prácticas docentes). Acentúa la importancia de los procesos } \\
\text { frente a los resultados y destaca los aspectos "comunicativos" } \\
\text { de la docencia. }\end{array}$ & Constructivista \\
\hline Emancipatoria & $\begin{array}{l}\text { Tiene acentuado el carácter moral y político en un amplio sen- } \\
\text { tido. La preocupación por la legitimación contextual de ciertos } \\
\text { objetivos y contenidos de la enseńanza, la vinculación entre las } \\
\text { prácticas de enseñanza y el marco político-social de las actua- } \\
\text { ciones de alumnos y profesores acentúan el carácter crítico y su } \\
\text { intencionalidad emancipatoria. }\end{array}$ & Crítico \\
\hline
\end{tabular}

Fuente: elaboración con base en Marrero (1993, pp. 251, 254-255).

Antes de cerrar este apartado, es importante mencionar los tres elementos que permiten calificar como novedad la categoría de las teorías implícitas, de acuerdo con los aportes de Marrero (2009, p. 35). Primero, porque considera la dimensión cultural como base del conocimiento cotidiano, superando así la frontera mentalista del cognitivismo; segundo, porque ofrece un modelo de mente dinámico que era una necesidad; y tercero, porque "conecta e integra en su funcionamiento tanto aspectos relacionados con el conocimiento y las creencias como la conexión de éstos con la acción». La conclusión es que mediante la categoría de las teorías implícitas se trata de explicar «cómo se organiza el conocimiento para actuar en interacción con el contexto cultural de elaboración».

\section{LA PROFESIÓN DOCENTE HOY. ALGUNAS REFLEXIONES}

Como se comentó al inicio de este texto, parte importante de los problemas que aquejan a las escuelas de hoy se atribuye al hecho de que la profesión docente -históricamente de menor estatus social que las demás profesiones- ha ido reduciéndose a un quehacer técnico. En este sentido, es urgente replantearnos acciones para restituirle las dimensiones filosóficas, teórico-científicas y artísticas que indebidamente se le han mutilado (Sarramona, 1997, pp. 81-82). Lograr esto desde luego que no es fácil y remite, entre otras cosas, a la necesidad de reformular el currículum que opera en las instituciones formadoras de docentes, y a poner en marcha programas de actualización-formación para los profesores en servicio, en donde se 
recuperen contenidos que fortalezcan su formación teórico-conceptual, sobre todo aquéllos orientados a desarrollar habilidades del pensamiento.

El propósito es emprender acciones para que los docentes reflexionen de manera crítica sobre su profesión, lo que significa la posibilidad de convertirlos en verdaderos agentes de cambio. Para lograrlo, de acuerdo con Fullan (2002, p. 15), se requiere como condición que ocurra un cambio fundamental de mentalidad (metanoia) en el que se asuma el cambio como parte de la cotidianeidad y no como algo transitorio o de carácter episódico.

Conseguir que los docentes sean profesionales reflexivos constituye un aspecto primordial en el análisis, pues sólo así se desempeñarán como profesionales de la docencia en el más amplio sentido del término, que incluya una firme y decidida actitud transformadora de su práctica. Ser un profesor cuya práctica docente esté sostenida en una reflexión crítica significa concebirse y actuar como un profesional que posee y aplica los diversos saberes señalados por Grossman (1990, citado en Marrero, 2010, pp. 234-235) que le permitan tener capacidad para lo siguiente:

1) Problematizar la concepción simplista de la pedagogía basada en una epistemología escolástica que responde a una racionalidad cartesiana y valorar opciones alternativas que den cuenta, de manera más objetiva, de los sujetos educativos y de los procesos que llevan a cabo. Dentro de estas pedagogías alternativas considerar aquélla que plantea el proceso de enseñanza aprendizaje «como un proceso permanente de reconstrucción conceptual, reestructuración continua de los modos de representación, comprensión y actuación, al calor de las experiencias y reflexiones que cada uno vive con los objetos, personas, ideas y contextos que rodean su existencia personal y profesional» (Pérez, 2010, p. 42). Esta epistemología constructivista se caracteriza, entre otras cosas, por plantearse trascender la concepción de la práctica como aplicación directa y lineal de la teoría, al considerarla como «un escenario complejo, incierto y cambiante donde se producen interacciones que merece la pena observar, relacionar, contrastar, cuestionar y reformular, al ser espacios y procesos generadores de nuevos conocimientos».

2) Analizar críticamente los contenidos que enseña, para lo que es esencial que tenga los conocimientos que le permitan discriminar entre textos que contienen saberes de sentido común y aquéllos con estatus científico porque se han obtenido mediante procedimientos metódicos con pretensión de validez, utilizando la reflexión sistemática, los razonamientos lógicos y respondiendo a una búsqueda intencionada (Ander Egg, 1998, p. 46).

3) Incorporar la investigación a su práctica pedagógica, es decir, como estilo de vida, lo que deberá traer aparejado un trabajo constante para formar en sus alumnos una actitud similar. Con base en la perspectiva de Mattew Lipman, es razonable y pertinente la propuesta de que los docentes cuestionen su actuación en el aula como simples transmisores de contenidos, para pasar a una práctica en la que conviertan sus clases en una 
... comunidad de investigación en la que los estudiantes se escuchan los unos a los otros con respeto, construyen sus ideas sobre las de los demás, se retan los unos a los otros para reforzar argumentos de opiniones poco fundadas, se ayudan en los procesos inferenciales a partir de lo que se afirma y buscan identificar los supuestos ajenos (1998, p. 57).

Este planteamiento de comunidad de investigación de Lipman embona bastante bien con la propuesta metodológica de investigación-acción en el aula, la cual para Elliot es un instrumento privilegiado de desarrollo profesional de los docentes:

... al requerir un proceso de reflexión cooperativa más que privada; al enfocar el análisis conjunto de medios y fines en la práctica; al proponerse la transformación de la realidad mediante la comprensión previa y la participación de los agentes en el diseño, desarrollo y evaluación de las estrategias de cambio; al plantear como imprescindible la consideración del contexto psicosocial e institucional no sólo como marco de actuación sino como importante factor de inducción de comportamientos e ideas; al propiciar, en fin, un clima de aprendizaje profesional basado en la comprensión y orientado a facilitar la comprensión (Pérez, 2000, p. 18; itálicas en el original).

4) Desarrollar una actitud crítica del modelo educativo en el que se inserta su práctica porque tiene los conocimientos necesarios para hacerlo. Para desarrollar dicha actitud, los docentes deberán identificar los modelos pedagógicos en que se sustenta dicho modelo educativo, es decir, detectar las teorías en que descansa, de manera que tiene los conocimientos y capacidades para explicar la relación entre ambos, saber que hay otros y con la certeza «de que siempre será válido y factible diseñar y sustituir unos modelos por otros» (Rosales, 2008, pp. 101-103).

5) Asumir una actitud crítica respecto a la institución en que trabaja, hacia el desempeño de sus colegas, ante los aparatos jerárquicos que ejercen el mando y frente a la diversidad de fenómenos que se le presentan en la realidad en que se desenvuelve. De igual manera, está dispuesto a recibir la crítica constructiva de otros miembros de la comunidad. Dado que los procesos educativos no se desarrollan en el aislamiento, sino en estrecha relación con su contexto, es necesario que, como profesionales de la educación, los docentes desarrollen un agudo ojo crítico de lo que sucede fuera del aula y actúen en consecuencia.

6) Interrogar de manera consciente e intencionada su pensamiento, su conocimiento y su comprensión, y que de ese interrogatorio resulte sacar del mundo obscuro de lo implícito aquellas teorías que obstaculizan su actividad profesional como docente para ponerlas bajo la potente luz de la reflexión. De ello deberá resultar una disposición de deshacer y rehacer su práctica profesional, de manera que se procure forjar un quehacer docente que se enfoque en facilitar un proceso de trabajo e intercambios donde se desarrollen y fomenten los valores educativos, es decir, aquéllos que capacitan «a los individuos para comprender la realidad compleja en que vive y para deliberar sobre los modos racionales de intervenir en la misma» (Pérez Gómez, 2000, p. 12). Lipman 
plantea que el profesor debe orientar acciones para desarrollar una práctica docente crítica, tomando cada vez mayor distancia de la práctica normal, es decir, de aquélla en la que la reflexión y la teoría están ausentes (1998, p. 54).

Lo anteriormente seńalado conduce a plantear la necesidad de crear condiciones para que los docentes abandonen el estatus de técnicos y pasen a ser profesionales de la enseñanza que, a la vez que tienen un adecuado dominio del conjunto de conocimientos inherentes a su campo que aplican con responsabilidad e inteligencia, se reconocen como individuos con hambre y sed de crecer como profesionales y como seres humanos; y, de esta manera, rebasar al sujeto cosificado para que emerja el sujeto pensante que se requiere en las aulas. En este sentido, es pertinente y necesario que los profesores tengan acceso a lecturas, ambientes y procesos que les conduzcan a promover los procesos de reflexión individuales y colectivos.

\section{REFLEXIONES FINALES}

Después de este recorrido por los constructos profesión docente y teorías implícitas de la enseñanza, y la relación entre ambos, se plantean como cierre tres reflexiones:

Primera. Para llevar a la práctica los puntos señalados anteriormente, los profesores deben vivir procesos profundos de autointerrogación y de interrogación por sus pares, para poner sobre la mesa del análisis las concepciones y creencias que, como dice Pozo (2002), llevan encarnadas en su mente. Conocer qué piensan sobre lo que ocurre en las aulas y por qué lo piensan, cuáles son las teorías implícitas que guían su práctica y cuál consideran que es su papel en los escenarios actuales de cambios dinámicos y complejos serán aspectos fundamentales para redimensionar la profesión docente de manera que esté a la altura de los requerimientos de las sociedades de nuestros días.

Segunda. En los tiempos actuales de nuevas exigencias a los sistemas educativos, en un mundo cada vez más globalizado en el que la injusticia y la desigualdad no sólo campean por doquier, sino que se incrementan cada día, es imprescindible reflexionar sobre el sentido y naturaleza de la tarea docente en aras de formar profesionales mejor preparados y más comprometidos con la tarea compleja de acompañar, estimular y orientar el aprendizaje y desarrollo de las cualidades humanas que se consideran más valiosas en las nuevas generaciones (Pérez, 2010, p. 33).

Tercera. Que los docentes hagan conciencia del relevante papel que juegan para transformar el anómalo estado de cosas imperante es quizá la tarea más urgente que enfrentan los sistemas educativos actuales. ¿Cómo lograrlo? Precisamente ahí radica el nudo gordiano y a dar pistas para desatarlo se enfocan las propuestas de estudiar el pensamiento de los profesores, que deben fluir tanto de arriba hacia abajo como de abajo hacia arriba. 


\section{REFERENCIAS}

Arévalo, R.M. (2010). «Teorías de dominio de los docentes sobre el aprendizaje y su expresión en la evaluación de los aprendizajes: un estudio de caso en una institución educativa particular de Lima». Educación, 19(36), 23-42, recuperado de http://revistas.pucp.edu.pe/index. php/educacion/article/view/2596.

Ander-Egg, E. (2001). Acerca del conocimiento y del pensar cientifico. Buenos Aires: LUMEN.

Canaleta-Safon, E. (2013). La construcción de la profesión médica en Mallorca durante la segunda mitad del siglo XIX. (Tesis doctoral). Universitat de les Illes Balears, recuperado de https:// www.tdx.cat/bitstream/handle/10803/112127/tecs1de1.pdf?sequence=1\&isAllowed=y.

Castorina, J.A., Barreiro, A. y Toscano, A. G. (2005). «Las representaciones sociales y las teorías implícitas: una comparación crítica». Educação \& Realidade, 30(1), 201-222, recuperado de http://www.redalyc.org/pdf/3172/317227040012.pdf.

Comenio, J.A. (1982). Didáctica Magna, Col. «Sepan Cuantos», n. ${ }^{\circ}$ 167. México: Editorial Porrúa.

Delval, J. (1999). Los fines de la educación. México: Siglo XXI Editores.

Dorfsman, M. (2012). «La profesión docente en contextos de cambio: El docente global en la Sociedad de la Información». RED-DUSC, Docencia Universitaria en la Sociedad del Conocimiento, 6 , recuperado de http://www.um.es/ead/reddusc/6.

Flexner, A. (1915). «Is a Social Work a Profession?». Proceedings of the National Conference of Charities and Correction at the Forty-Second Annual Session Held in Baltimore, Maryland, May 12-19. Chicago, Illinois: The Hildmann Printing Co. 576-590, recuperado de https:// socialwelfare.library.vcu.edu/social-work/is-social-work-a-profession-1915/.

Freidson, E. (2001). «La teoría de las profesiones. Estado del arte». Perfiles Educativos, XXIII (93), 28-43, recuperado de http://www.scielo.org.mx/scielo.php?script=sci_arttext\&pi$\mathrm{d}=$ S0185-26982001000300003.

Freire, P. (1981). La educación como práctica de la libertad, 28. a ed. México: Siglo XXI Editores.

Fullan, M. (2002). Las fuerzas del cambio. Explorando las profundidades de la reforma educativa. Madrid: Akal.

Gómez, V. y Guerra, P. (2012). «Teorías implícitas respecto a la enseñanza y el aprendizaje: ¿Existen diferencias entre profesores en ejercicio y estudiantes en pedagogía?». Estudios Pedagógicos, 38(1), 25-43.

Goodson, I. y Hardgreaves, A. (eds.) (1996). «Teachers' professional Lives: Aspirations and Actualities», en Goodson, I. y Hardgreaves, A. (eds.). Teacher's Professional Lives. New Prospect Series 3. London: Falmer Press.

Hernández, G. (2008). "Teorías implícitas de lectura y conocimiento metatextual en estudiantes de secundaria, bachillerato y educación superior». Revista Mexicana de Investigación Educativa, 13 (38), 737-771, recuperado de http://www.scielo.org.mx/scielo.php?pi$\mathrm{d}=$ S1405-66662008000300004\&script=sci_arttext.

Hortal, A. (2002). Ética General de las profesiones, 2. ${ }^{a}$ ed. Bilbao: Editorial Desclee de Brouwer.

Lazcano. X., Santa Cruz, J., y Conget, P. (2013). «Teorías implícitas sobre la enseñanza y su asociación con las prácticas pedagógicas de os docentes de la carrera de Medicina». Educación de Ciencias de la Salud, 10(1), 47-52, recuperado de http://www2.udec.cl/ofem/recs/anteriores/vol1012013/artinv10113h.pdf. 
Lipman, M. (1998). Pensamiento complejo y educación. Madrid: Ediciones de la Torre.

Marrero J. (1993). «Las teorías implícitas del profesorado: vínculo entre la cultura y la práctica de la enseñanza», en Rodrigo, M.J., Rodríguez, A. y Marrero, J. Las teorías implícitas: una aproximación al conocimiento cotidiano (243-276). Madrid: Visor.

Marrero, J.E. (2009). «Escenarios, saber y teorías implícitas del profesorado», en Marrero, J.E. (ed.). El pensamiento reencontrado (8-45). Barcelona, España: Editorial Octaedro.

Marrero, J.E. (2010). «El currículum que es interpretado. ¿Qué enseñan los centros y los profesores y profesoras?», capítulo IX, en Gimeno SACRISTÁN, J. (comp.). Saberes e incertidumbres sobre el curriculum (221-245). Madrid: Morata.

Nóvoa, A. (2009). «Profesores: ¿el futuro aún tardará mucho tiempo?», en Velaz de Medrano, C. y Vaillant, D. (2009). Aprendizaje y desarrollo profesional del docente (49-56). Madrid: Fundación Santillana.

Oficina Internacional del Trabajo de Ginebra (1995). Formación profesional. México: Oficina Internacional del Trabajo y Alfa Omega.

Palacios, J. (1997). La cuestión escolar. Criticas y alternativas. Barcelona, España: Editorial Laia.

Panaia, M. (2008). Una revisión de la sociología de las profesiones desde la teoría critica del trabajo en la Argentina, Col. Documentos de proyecto. Santiago de Chile: CEPAL, recuperado de http://centroderecursos.cultura.pe/sites/default/files/rb/pdf/sociologia\%20de\%20las\%20 profesiones.pdf.

PÉrez, A.I. (2000). «Introducción. Comprender y enseñar a comprender. Reflexiones en torno al pensamiento de J. Elliot», en Elliot, J. La investigación-acción en educación (9-19). Madrid: Ediciones Morata.

PÉREz, Á.I. (2010). «Nuevas exigencias y escenarios para la profesión docente en la era de la información y de la incertidumbre». Revista Interuniversitaria de Formación del Profesorado, 24(2), 17-36, recuperado de http://www.redalyc.org/html/274/27419198002/.

PÉrez, A.I. (2010). «Aprender a educar. Nuevos desafíos para la formación de docentes». Revista Interuniversitaria de Formación del Profesorado, 24(2), 37-60, recuperado de http://www. redalyc.org/html/274/27419198003/.

Pozo, J.I. (2002). «La adquisición de conocimiento científico como un proceso de cambio representacional». Investigaçóes em Ensino de Ciências, 7(3), 245-270, recuperado de https://repositorio.uam.es/bitstream/handle/10486/666207/adquisicion_pozo_iec_2002.pdf?sequence=1.

Rivero García, A. y Porlán Ariza, R. (1998). «La naturaleza del conocimiento profesional deseable del profesorado». Enseñanza de las ciencias, 16(2), recuperado de http://ddd.uab.cat/pub/ edlc/02124521v15n2p155.pdf.

RodríGuez, J.A. y Guillén, M.F (1992). «Organizaciones y profesiones en la sociedad contemporánea». Revista Española de Investigaciones Sociológicas, 59, 9-18, recuperado de https://dialnet.unirioja.es/servlet/articulo? codigo $=250110$.

Rosales, M.A. (2004). «Revolución tecnológica, globalización y profesión docente», en Cano, J.G. y Lara, J.J. (coords.). Globalización y crisis. Contribuciones al debate en el ámbito social y educativo. Culiacán, Sinaloa: El Colegio de Sinaloa y UAS, 191-237.

Rosales, M.A. (2008). «Aportes iniciales para una teoría de modelos». Acción Educativa, Revista de la Facultad de Ciencias de la Educación, enero-diciembre, UAS, Culiacán, Sinaloa, 94-103. 
Rosales, M.A. (2009). La formación profesional del docente de primaria. México: Plaza y Valdez Editores y Universidad Pedagógica Nacional.

SchöN, D. (1998). El profesional reflexivo. Cómo piensan los profesionales cuando actúan. España: Paidós. Sarramona, J. (1997). Fundamentos de educación. Barcelona, España: Ediciones CEAC.

Spencer, H. (1992). «Los orígenes de las profesiones». Caps. I y Xir. Revista Española de Investigaciones sociológicas, 59, 315-325, recuperado de http://www.reis.cis.es/REISWeb/PDF/ REIS_059_16.pdf. 